\title{
Influence of environment and aging materials on the performance of solar chimney power plants
}

\author{
Salim Mekki Boualleg ${ }^{1,2, *}$, Salah Larbi ${ }^{1}$, Amor Bouhdjar $^{3}$, Dalila Amokrane ${ }^{2}$, and Abdallah Sofiane Berrouk ${ }^{4}$ \\ 1 Mechanical Engineering Department, Ecole Nationale Polytechnique, 10, Avenue Hassen Badi, El Harrach 16200, Algiers, \\ Algeria \\ 2 Departement des Energies Nouvelles et Renouvelables, Institut Algérien du Pétrole, Avenue du 1er Novembre 35000 , \\ Boumerdes, Algeria \\ ${ }^{3}$ Centre de Développement des Energies Renouvelables, Bouzareah, Algeria \\ ${ }^{4}$ Mechanical Engineering Department, Khalifa University of Science and Technology, United Arab Emirates
}

Received: 9 February 2021 / Received in final form: 25 March 2021 / Accepted: 25 March 2021

\begin{abstract}
The simplicity of solar chimney power plant (SCPP) makes it very attractive for power generation. This paper investigates the technical feasibility of using a locally-produced plastic film (Low-Density PolyEthylene "LDPE") as a solar chimney power plant collector cover. The idea is to combine a very low-cost material with a simple technical solution. As LDPE is subject to deterioration, the effect of aging on the initial properties of the used material is analyzed. Natural aging was privileged over the accelerated one by exposing the studied film, for a time duration of 3 years, to environmental constraints similar to the local conditions where the SCPP collectors are installed. Various experimental tests were carried out to show the decrease of mechanical resistance and to confirm the structural degradation. Results showed that after an exposure time of 3 years, a decrease of more than $50 \%$ of the failure stress is recorded. The spectroscopic analysis confirmed the progressive degradation of the structure of the aged films. Pyranometric measurements showed that the transmittance of the film proportionally decreases with the duration of aging which has a direct impact on the SCPP collector performance. A mathematical model is developed and validated to simulate the performance of the SCPP. An increase in the initial dimension of the collector by about $23 \%$ is necessary to maintain the design-targeted production during an exploitation period of three years. The study concluded that this type of film can be used in SCPP collectors for a maximum life cycle of 3 years under the considered environmental conditions.
\end{abstract}

\section{Introduction}

The Global Energy Scenario reveals that renewable sources from biofuels, wind energy and solar energy will have the highest contribution in the energy mix in the next future [1]. This will reduce the concentration of carbon dioxide, $\mathrm{CO} 2$, in the atmosphere and hinder the increase of the earth's average temperature [1].

In its energy transition policy, Algeria is targeting to produce $22 \mathrm{GW}$ of renewable energies by 2030 , through its displayed national program (Algerian Ministry of Energy) [2]. However, the technological choice is a key component of sustainable development. In this view, the technological simplicity of solar chimney power plant (SCPP) makes it

\footnotetext{
* e-mail: salimmekki.boualleg@gmail.com; salim_mekki.boualleg@g.enp.edu.dz
}

very attractive for sunny countries like Algeria. It presents many advantages, such as its simple design which can provide about $200 \mathrm{MW}$ of electric power while being safe, reliable and requiring minimum maintenance. However, a commercial SCPP is a very huge structure. The economic optimization of such power plant can be achieved using cheap construction materials for collectors in order to offset the significant cost linked to building chimneys made of concrete.

SCPP consists of three main components: the solar collector, the chimney tower and the turbine (Fig. 1). Historically, Prof. Bernard Dubos proposed in 1926 the construction of a SCPP in North Africa to the French Academy of Sciences [3]. The first solar chimney power plant prototype $50 \mathrm{~kW}$ was built in Manzanares, Spain. It had a braced metal chimney of $194.6 \mathrm{~m}$ high, $0.00125 \mathrm{~m}$ thick and a collector with a radius of $122 \mathrm{~m}$, covered by a plastic and glass roof [4]. 


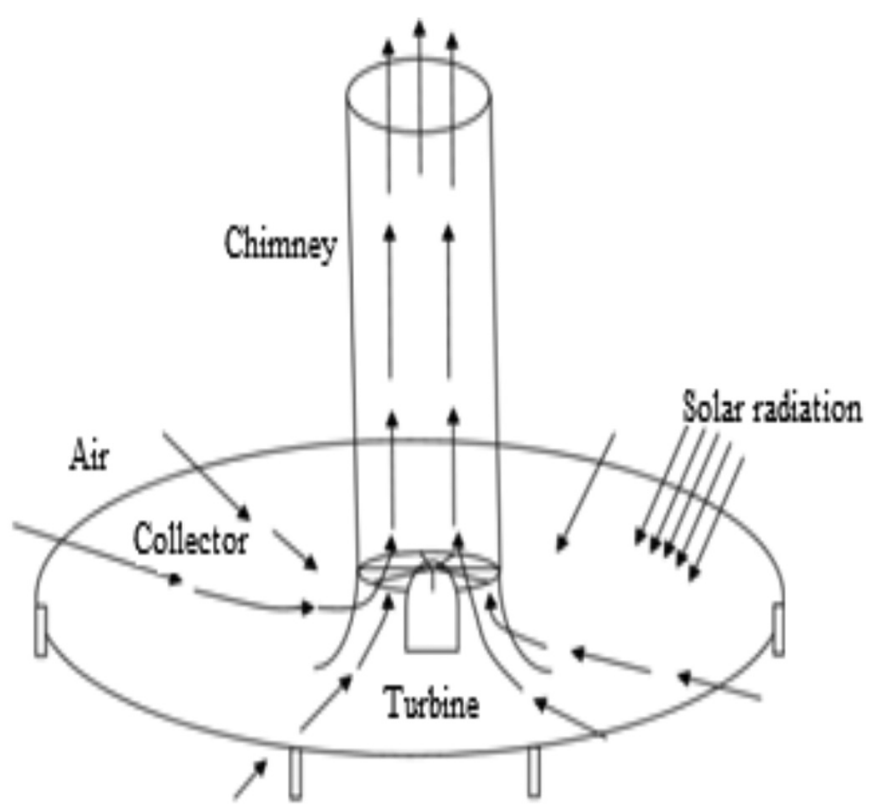

Fig. 1. Main components of a solar chimney power plant.

Haaf et al. [4] and Haaf [5] analyzed the energy balance, the design criteria and the cost analysisof SCPPs. The authors showed that the use of a plastic film of PVC and PVF offers an optimal recovery time of 3.6 years for a 36 MW SCPP. The Manzanares prototype of the solar chimney power plant operated for eight years (from 1982 to 1989) [5]. This pioneering work has been followed by many theoretical and experimental studies for modeling large scale SCPP. Based on an analytical model, Schlaich [6] demonstrated that there are no optimal dimensions for a solar chimney. However, if the cost of implementation is taken into consideration, the plant can be optimized thermodynamically. This conclusion showed the importance of the present work as it investigates the use of cheaper material. In their research, Schlaich et al. [7] and Schlaich and Schiel [8] analyzed the extrapolation of experimental data from the prototype of Manzanares to large power plants (5, 30 and $100 \mathrm{MW})$.

Located in the Jinshawan desert region of Inner Mongolia, the Wuhai SCPP [9] prototype was connected to the grid in October 2010. The various measurements showed that the surrounding winds have a significant influence on the airflow inside this plant. In 2011, Najmi et al. [10] suggested the use of asphalt or rubber at the bottom of the collector, a double glazed glass for the roof with a reduction of collector height to $1.3 \mathrm{~m}$ to increase the power of the system.

In a comparative investigation of different analytical models, Boualleg et al. [11] pointed out that the different studies presented in the literature, considered constant physical material parameters through the life cycle of SCPP exploitation. Dogan et al. [12] experimented a new concept of perforated solar collector to enhance the performance of SCPP. The authors reported that the collector efficiency is three times higher than the conventional one, which can reduce considerably the large solar collector.

One year later, the authors [13] proposed the hybridization of the prototype with photovoltaic panels and reported that system's efficiency increased by about $2 \%$. In order to highlight the impact of the collector roof height on the SCPP performance, Ayadi et al. [14] built an experimental prototype at the University of Sfax, Tunisia, North Africa. They concluded that a decrease in the height of the collector roof yield to an increase in the generated power. However, they did not give any reference to the value of the optimal height of the collector related to the dimension of the structure. A review by Molana et al. [15] reported that experimental studies were mainly focused on small-scale systems. The study did not analyze the impact of aging on the performance of the system. The research strongly suggested the building of large power plants to provide more reliable references for theoretical and modeling studies. It concluded that the choice of materials mainly depends on the resulting power generating costs. In their review article, Penghua et al. [16] demonstrated that with the research and development of construction technology, new materials, and novel concepts, the SCPP will possibly play an important role in increasing energy supplies, by improving the energy mix, and alleviating environmental concerns.

Al-Kayiem et al. [17] investigated the enhancement of a solar chimney, by recovering thermal waste energy of exhaust gases to heat the air in the solar chimney collector.

In their study, Nasraoui et al. [18] performed a new collector design with double-pass counter flow mode, which allowed the increase of its efficiency by $28 \%$. In their study, Siamak et al. [19] proposed the use of a semi-transparent photovoltaic panels as the collector roof of a solar chimney collector for economic enhancement of the system. Using a three-dimensional simulation, Seyyed et al. [20] compared the case of collector with natural and artificial roughness. They investigated its impact on the performance of SCPP in the region of Semnan, Iran. Sedighi et al. [21] investigated the effects of soil porosity on the output power and energy efficiency of SCPP. They found that land with less porosity and a location with high radiation is the most suitable place for the construction of solar chimney power plant.

Papadakis et al. [22] explained that testing methods used for plastics in general, are also applied to greenhouse covers despite important functional differences. Hence the urgent need for establishing widely accepted internationally testing methods and standards for testing the physical properties of greenhouse covering materials. In their review, the authors underlined the excellent radiation transmissivity of LDPE films. They reported that, this covering material is dominant and most inexpensive plastic film in the Mediterranean regions.

Dehbi et al. [23] investigated the influence of different exposure times of natural ageing on the mechanical behavior of mono-layer and tri-layers LDPE films used as greenhouse cover. The authors explained that the design of tri-layers film makes it possible to slow down the deterioration of the film, making it more durable. 
Dilara et al. [24] discussed several methods for testing the mechanical properties of greenhouse polyethylene films. Also, the factors affecting ageing of LDPE used as greenhouse covering are presented. The authors reported that the artificial ageing testing can only provide a rough estimate of the actual behavior of the plastic film when exposed to the real and complicated environmental factors that affect the plastic during its use.

The review of the previously published studies showed few works that carried out experimental studies and evaluated effect of ambient conditions on properties of the materials. The different simulation models, in the literature, assume constant thermo-physical properties without any loss in power production even when using polymers canopy for the experimental setup. The present work goes beyond the evaluation of the material degradation, by analyzing its impact on the performance of SCPP and, the reduction of solar transmittance on the system efficiency.

This study investigates the impact of aging on the performance of the SCPP facility by analyzing the use of greenhouse stabilized LDPE film for mainly two reasons: (i) enhance the economic efficiency of these power plants by using cheaper material and, (ii) demonstrate the impact of aging on the SCPP performance.

\section{SCPP collector description}

The solar collector (SC) is the part of SCPP, which produces hot air by the greenhouse effect. With a roof made of glass or clear plastic film, SC covers a very large area of several thousand square meters. The choice of the material covering this type of collector has a direct and important impact on the initial investment, and hence the importance of the choice of the material to be used [6].

Indeed, covering the huge collector structure, up to several hectares, with low density polyethylene (LDPE), will reduce the initial investment costs, as well as the duration of the pay-back period, making the SCPP more economically attractive. However, the degradation of the film affects its performance. It alters its mechanical and photo-thermal performance and consequently reduces the overall efficiency of the system.

In this view, the LDPE film, produced locally and widely used in agricultural greenhouses in Algeria, can be interesting as an alternative solution to glass based on its low price and physical and thermal properties. The popular use of plastic is due in part to its cheapness and to the fact that there is not a single form of plastic but a multitude with specific properties for each. They can be rigid or flexible, transparent or opaque, electrically insulating or semiconductors, insensitive to moisture, and lightweight compared to glass [25]. In addition, the multitude of manufacturing processes makes it possible to easily obtain and without machining complex forms. However, polymers often deteriorate in outdoor applications. The most important cause of degradation is solar irradiation; the lifetime of plastics depends mainly on the climate. The higher the temperature, the faster the chemical reactions making plastics vulnerable in hot climates [26].

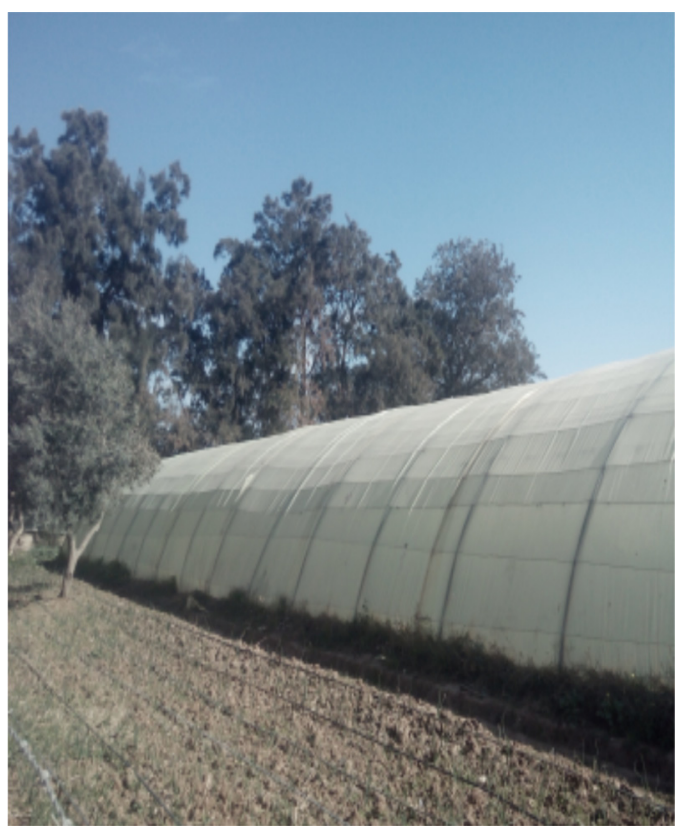

Fig. 2. LDPE specimen used in greenhouse located in Boumerdes.

A photo-degradation study of non-stabilized transparent and non-colored polyethylene films Adelhafidi et al. [27] reported that after 8 months of exposure time, the samples became too brittle to not resist the wind force. In the present study a yellowish stabilized LDPE is considered.

\section{Experimental protocol}

Since the plastic cover of a solar chimney collector is subjected to mechanical and climatic constraints (irradiation, wind, rain, high temperature gradients ...), this will accelerate its degradation. The performance of a SCPP collector will be influenced by these phenomena and hence impact the efficiency of the whole system. Prior to degrading the film, a characterization of new (virgin) samples was carried out.

\subsection{Aging polyethylene films}

To privilege the natural aging, the same film was used in a greenhouse installed in the region of Boumerdes (Fig. 2) and exposed to environmental constraints similar to that of a SCPP installed in the same region.

At different exposure times, samples were tested (1 month, 2 months, 1 year, 2 years and 3 years). Mechanical, Hardness, rheological, physical, spectroscopic and photo-thermal tests were performed on sample films of the same nature.

\subsection{Mechanical properties}

A tensile test was performed according to ISO 1184 standard using a rectangular form and a speed of $100 \mathrm{~mm} / \mathrm{min}$. This test determined the strength at break, Young's modulus and elongation at break (Fig. 3). 


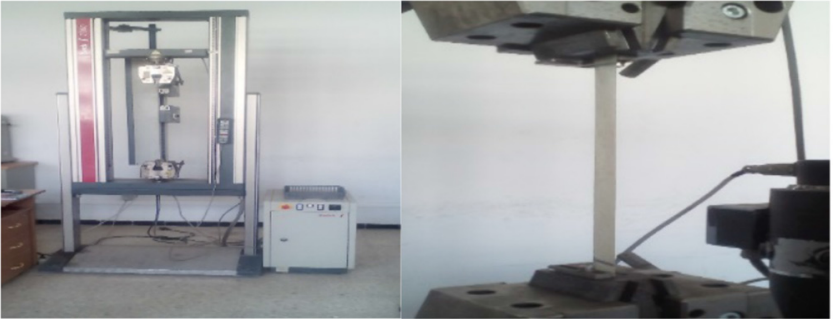

(a)

(b)

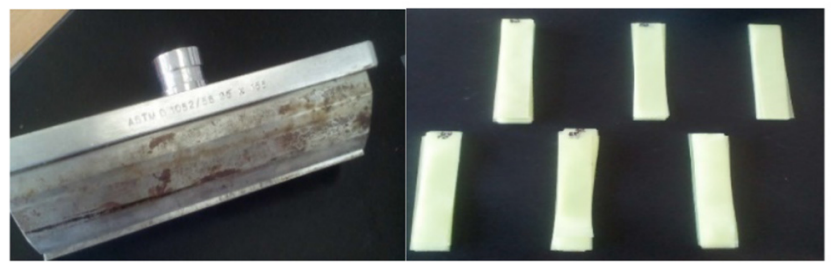

(c)

(d)

Fig. 3. Tensile Test performed at Polymer laboratory IAP: (a) Device for tensile tests on plastic films, (b) Parallel clamping specimen grips (c) Matrix for specimen cutter (d) Specimens to be tested.
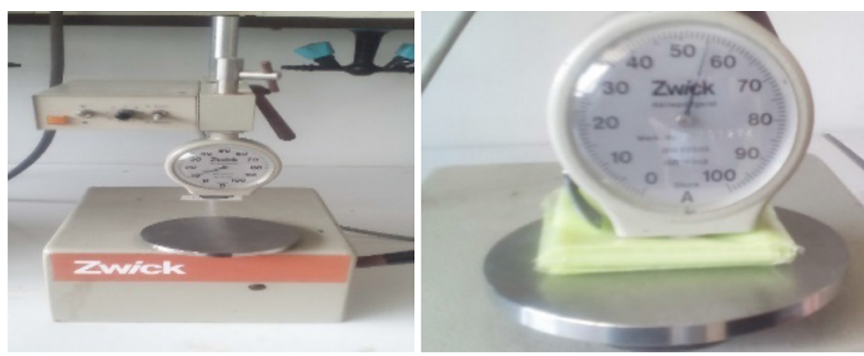

Fig. 4. Hardness tester at Polymer laboratory IAP.

The Hardness test was performed according to ISO 868-1978 shore A (Fig. 4).

\subsection{Rheological properties}

\subsubsection{Flow rate index}

The melt flow index (MFI) was done according to the standard ISO 1133-1918 (F) using the temperature of $190 \pm 0.5^{\circ} \mathrm{C}$ and a load of $2160 \mathrm{~g}$ (Fig. 5a).

\subsubsection{Melting temperature}

Measurement of the melting temperature was determined using "Kofler bench" (Fig. 5b).

\subsection{Physical properties}

The density was carried out according to the ISO 1186 standard using the immersion method.

\subsection{Spectroscopic methods}

Spectroscopic ultraviolet-visible (UV-Visible) and infrared (IR) measurements were performed mainly for a qualitative

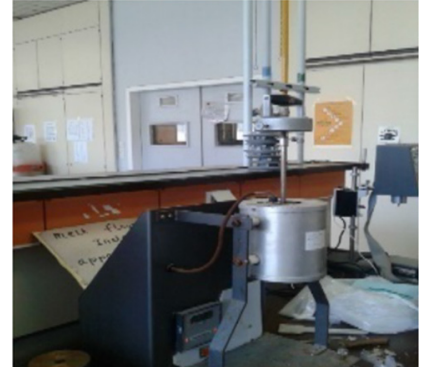

(a)

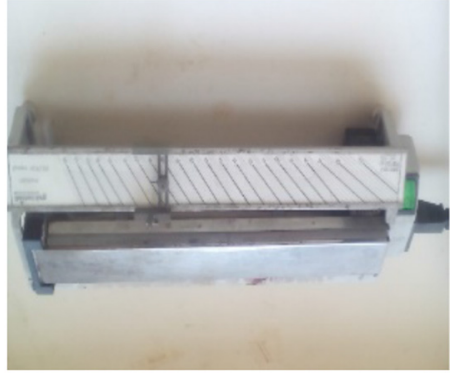

(b)
Fig. 5. Polymer rheological laboratory at IAP: (a) The melt flow index tester; (b) Kofler bench.

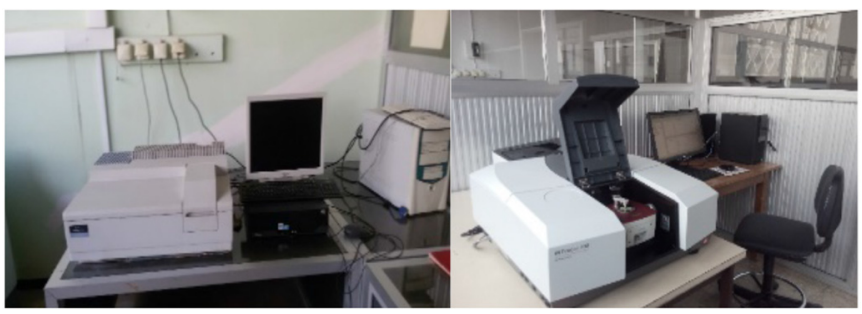

(a) (b)
Fig. 6. Spectroscopic Laboratory IAP: (a) UV-Visible spectrophotometer (b) Fourier Transform Infrared Spectrophotometer.
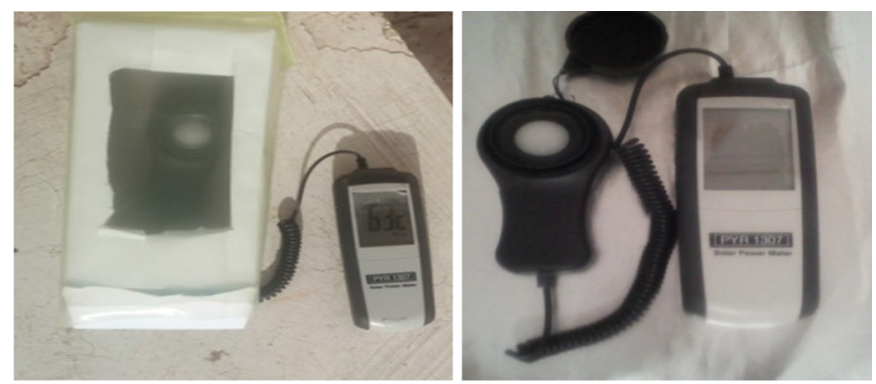

Fig. 7. Photo thermal measurement dispositive.

determination prior to following the evolution of degradation of LDPE samples (Fig. 6).

\subsection{Photo thermal properties}

Measurement of the global and incident direct solar radiation was performed by means of a pyranometer. The test was firstly performed without a film barrier; secondary inside boxes covered with virgin, and finally with aged films to compare the transmittance as a function of the exposure time. The used dispositive is shown in Figure 7. It consists of a box with an opening. The opening is covered with a sample from the tested film. Cares were taken to avoid shadow effect on the measurement, which makesthe estimation of solar transmittance of the film possible. 
Table 1. Characteristics of the virgin plastic film sample.

\begin{tabular}{llll}
\hline Properties & & Results & Units \\
\hline Melt Flow Index $(\mathrm{MFI})$ & & $0.66 \pm 0.007$ & $\mathrm{~g} / 10 \mathrm{~min}$ \\
Density $(\boldsymbol{\rho})$ & & $0.913 \pm 0.011$ & $\mathrm{~g} / \mathrm{cm}^{3}$ \\
Melting temperature $\left(\mathrm{T}_{\mathrm{f}}\right)$ & 123 & ${ }^{\circ} \mathrm{C}$ \\
Hardness & & $56 \pm 3.22$ & Shore A \\
& Longitudinal & $1.76 \pm 0.04$ & $10 \mathrm{E} 9 \mathrm{~N} / \mathrm{mm}^{2}$ \\
Young's modulus $(\mathrm{E})$ & Transversal & $1.95 \pm 0.10$ & $\mathrm{~N} / \mathrm{mm}^{2}$ \\
Stress at break $(\sigma)$ & Longitudinal & $21 \pm 0.91$ & $\%$ \\
Elongation at break $(\varepsilon)$ & Transversal & $21 \pm 0.63$ & $\%$ \\
\hline
\end{tabular}

\section{Results and discussion}

To ensure the data reproducibility, large square samples sides were cut, at each ageing period, from the same main cover, and sufficient test samples were prepared to conduct the experiments required, with respect to the recommendations of the used standard.

\subsection{Virgin film characterization}

The obtained results related to the virgin film being considered in this study are reported in Table 1 . The obtained value of the MFI is that of a polyethylene (PE) grade used for an injection-blowing process (Recueil de norms SdandardISO 21 [28]). Regarding density, the obtained result shows that it is in the range of [0.91$0.92 \mathrm{~g} / \mathrm{cm}^{3}$ ] (Recueil de normes ISO 21, 1984). The melting temperature of the film was $123^{\circ} \mathrm{C}$. This result is included in the melting temperature range of low density polyethylene $\left[100,125^{\circ} \mathrm{C}\right]$. In conclusion, the results of the melting point and density tests confirm that the new virgin film is a low-density polyethylene type.

\subsection{Aging film characterization}

\subsubsection{Tensile test}

Figures 8 and 9 represent the stress at break of aged samples versus the exposure time in the two directions longitudinal and transversal respectively (Longitudinal direction refers to the extruding machining direction during the plastic film production process; the opposite direction of the sample is the transversal direction). The obtained results show that the stress at break decreases considerably as a function of exposure time. It should also be noted that this decrease is a function of the climatic conditions, depending on the months and season, as is the case for 1 and 2 months of exposure where the variation is not very significant and remains of the same order of magnitude for both directions (longitudinal and transversal). After an exposure of 3 years, however, a considerable reduction of more than $50 \%$ of properties is observed.

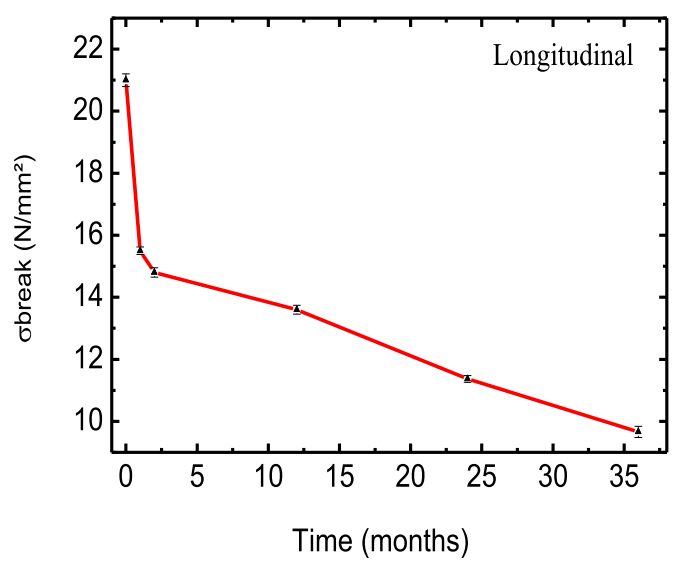

Fig. 8. Stress at break of LDPE in longitudinal direction.

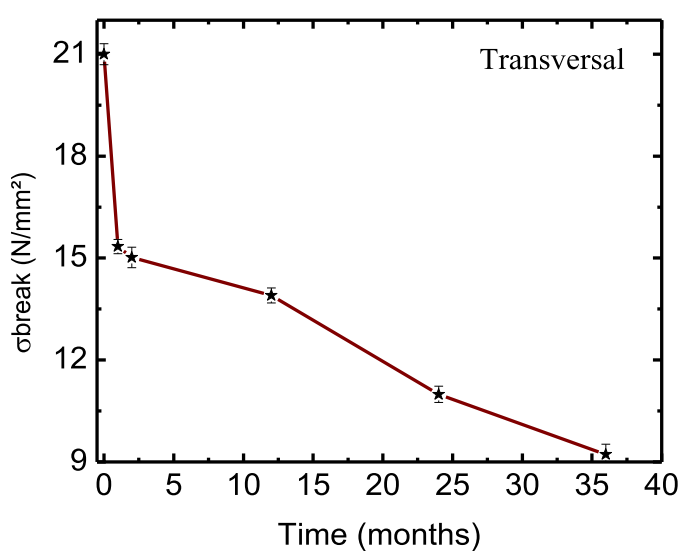

Fig. 9. Stress at break of LDPE in transversal direction.

Dehbi et al. [23] used a milky colored LPDE present on the market. The new sample of mono layer LDPE reviled very low stress at break of about $2 \mathrm{MPa}$ [23], when it should be of a minimum of $8 \mathrm{MPa}[29]$. They found that lifetime of this type of mono-layer LDPE is around 5 onths, and when multi layering the film it doubles the cover life time 


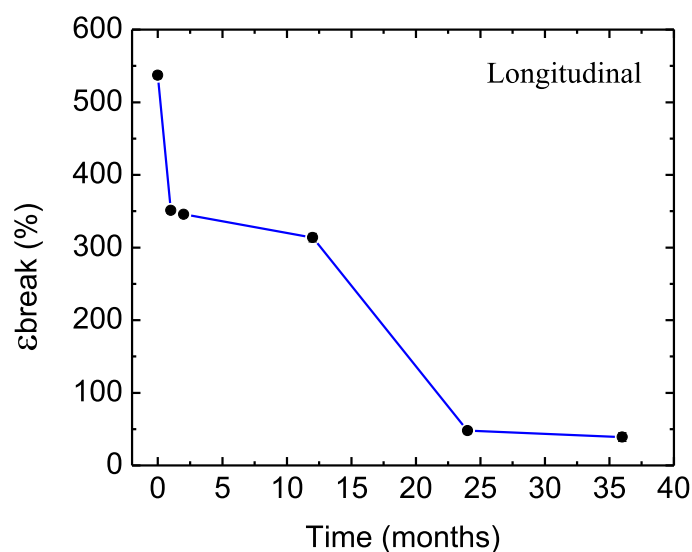

Fig. 10. Elongation at break of longitudinal LDPE.

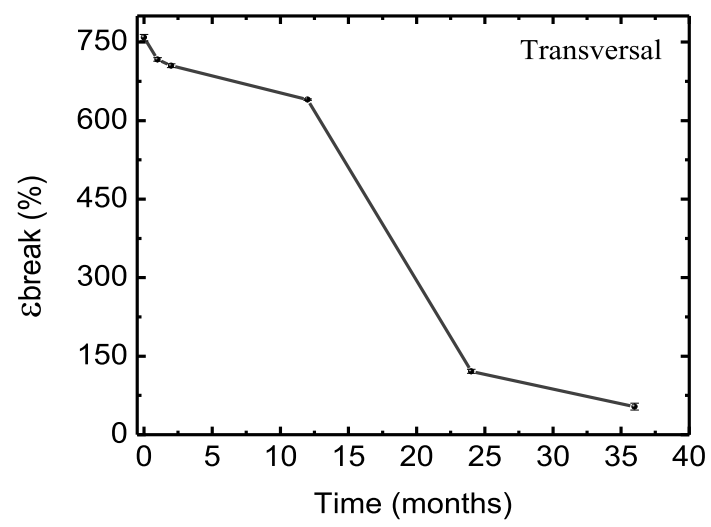

Fig. 11. Elongation at break of transversal LDPE.

Table 2. Hardness results of the films.

\begin{tabular}{llllll}
\hline Measurements & Virgin & 1 month & 2 months & 24 months & 30 months \\
\hline 1 & 55 & 58 & 53 & 48 & 45 \\
2 & 61 & 53 & 52 & 46 & 43 \\
3 & 57 & 53 & 50 & 48 & 44 \\
4 & 51 & 56 & 47 & 43 & 46 \\
5 & 56 & 57 & 57 & 47 & 42 \\
Average (Shore A) & $56 \pm 1.61$ & $55.4 \pm 1.02$ & $51.8 \pm 1.65$ & $46.4 \pm 0.92$ & $44 \pm 0.70$ \\
\hline
\end{tabular}

reaching 10 months for tri-layers film. In the present case, the yellowish green film reached a 3 years life time and registered an initial $\sigma_{\text {break }}$ of $21 \mathrm{Mpa}$. Those results are in good agreement with [22] and [29].

Figures 10 and 11 show the variation of the elongation at break as a function of time in the two directions (longitudinal and transversal respectively). A similar trend with the tensile stress was obtained. A significant decrease in elongation at break as a function of exposure time is observed after an exposure of 3 years.

A similar trend with the tensile stress was obtained. A significant decrease in elongation at break as a consequence of exposure time is observed after an exposure of 3 years.

Figures 12 and 13 illustrate the variation of Young's modulus as a function of the exposure time in both directions.

The obtained results show an evolutionary decrease of the modulus of elasticity for the aged film compared to the new samples.

\subsubsection{Hardness test}

The obtained results of hardness shore A for virgin and aged samples are summarized in Table 2 .

It can be noted from the obtained results that the hardness shore A decreases with the duration of exposure and this is a function of the climatic constraints (wind, temperature, rain, solar radiation, humidity). These results are in agreement with the tensile tests.

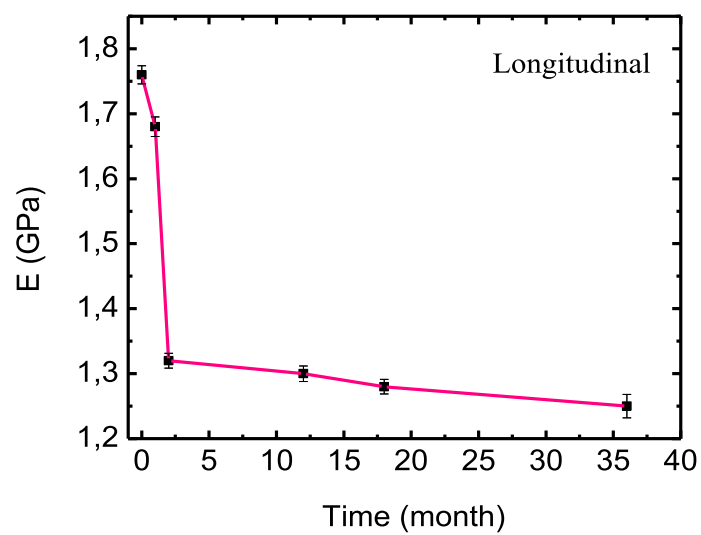

Fig. 12. Young's modulus of longitudinal LDPE.

\subsection{Spectroscopic tests}

\subsubsection{UV-Visible spectroscopy}

Figure 14 representing UV-Visible spectroscopy results showed that the new PE film has a minor absorption band at $308 \mathrm{~nm}$, indicating the presence of chromophores or double bonds. Such results may be due either to the primary antioxidants, additives used to stabilize the film from thermo-oxidative degradation, or to the dye, an additive used for coloration (yellow pigment). After aging, new peaks appear mainly at $319,321,323$ and $327 \mathrm{~nm}$ for films aged 1, 2, 18 and 36 months, respectively. The 


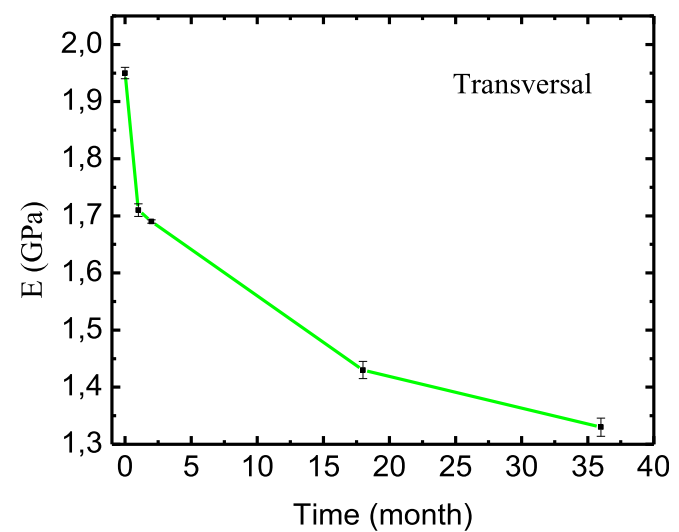

Fig. 13. Young's modulus of transversal LDPE.

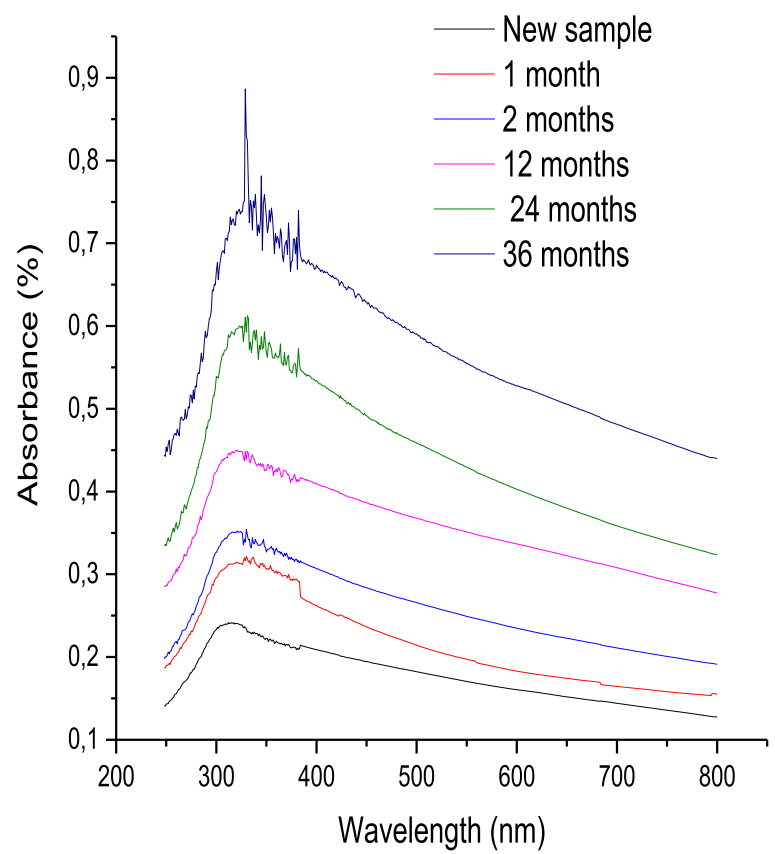

Fig. 14. UV-Visible spectroscopy results of new and aged samples.

intensity and frequency of these peaks increase with the duration of exposure. These traduce the increase in the number of double bonds: the higher the number of double bonds the more important is the bathochromic effect (wavelength increases) and the hyperchromic effect (intensity absorption increases).

\subsubsection{Infra-Red (FTIR) spectrometry}

Figure 15 represents the transmittance as a function of wavenumber for the naturally aged films in comparison with the new one. The obtained results illustrate the presence of a peak at $1734 \mathrm{~cm}^{-1}$ corresponding to $\mathrm{C}=\mathrm{O}$ absorption. Knowing that PE is apolyolefin polymer, such result is may be due to antioxidants or pigments structure. It has been also noticed that the peak intensity of $\mathrm{C}=\mathrm{O}$ bond increases with film aging. Furthermore, two peaks at

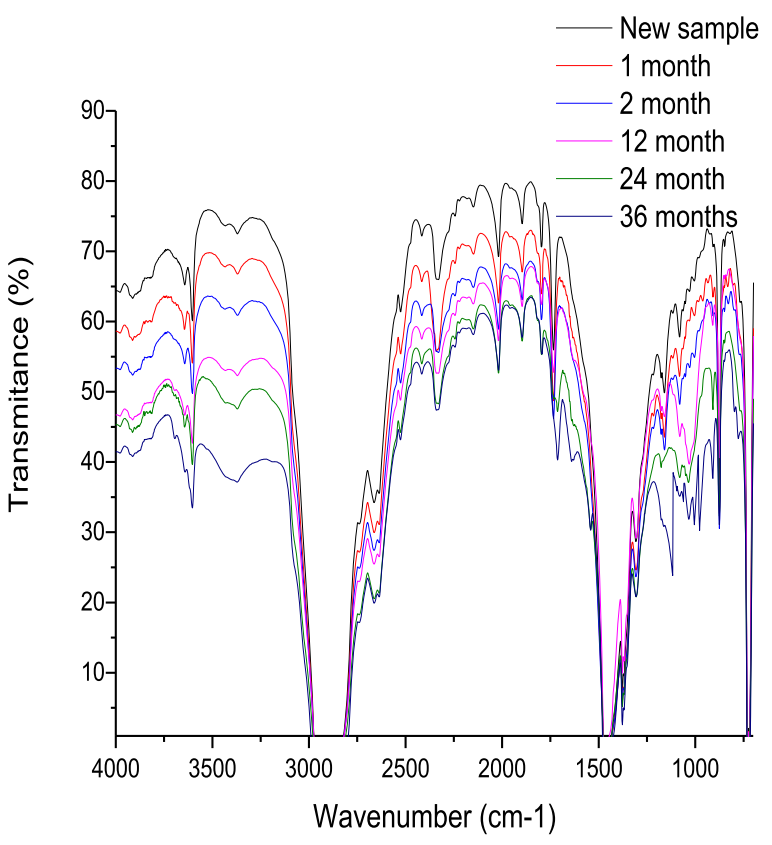

Fig. 15. FTIR results of the new and naturally aged films.

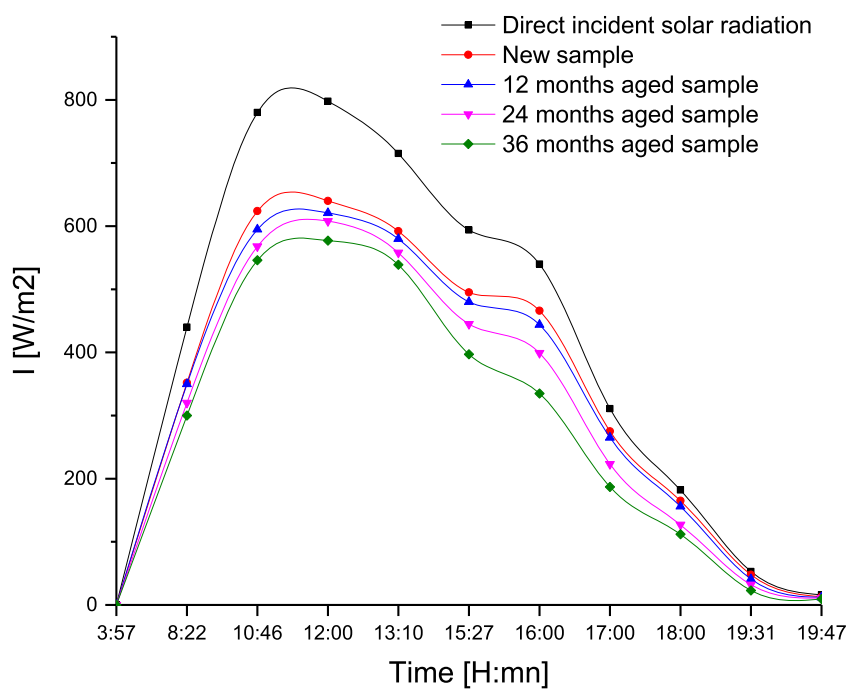

Fig. 16. Transmitted solar irradiation on the 18th of July 2019, measured for direct incident solar irradiation, and incident through a new sample, 12, 24 and 36 months exposed sample.

880 and $3600 \mathrm{~cm}^{-1}$ were observed, reflecting the presence of $\mathrm{N}=\mathrm{H}$ and $\mathrm{O}-\mathrm{H}$ absorption bonds. These later are attributed to the yellow pigment present initially in the samples. These results are in good agreement with those obtained by UV-Visible spectroscopy.

\subsection{Photo-thermal measurement}

The measurements were performed on the 18th of July 2019 , a summer day with a clear sky. The obtained results of solar irradiation and transmitted radiation through virgin and 3 years aged sample are shown in Figure 16. 
Defining the transmittance as $\tau=\frac{\mathrm{I}}{\mathrm{I}_{0}}$, where $\mathrm{I}_{0}$ and $\mathrm{I}$ are direct and indirect incident irradiation measured without and through film obstacle, respectively. The average solar radiation transmission $\tau$, of a new sample is about $80 \%$, which is in the range of transmittance of the plastic film [70-95\%] as reported in [22]. It reaches $78 \%$ after one-year exposure (12 months). It decreases to $72 \%$ in the second years and $64 \%$ after 3 years exposure. This corresponds to a progressive reduction of solar transmission of $2.5 \%, 10 \%$ and $20 \%$ during the first, the second and the third year, respectively. These results are consistent with the results obtained by FTIR spectrometry as degradation increase with aging duration leads to a transmittance reduction. As the incident energy converted to heat by the system is proportional to $\tau$, the reduction of the film transmittance will reduce the overall effective energy produced by the system. This will be investigated in more details in the next section.

\section{Mathematical model}

The simulation is based on an analytical model based on an energy balance applied to the collector. Thus a relationship between the mass air flow and the temperature gain is introduced. This relationship will be coupled to the chimney model, to represent the complete system. The goal is to determine the energy produced based on the geometric parameters and physical properties of the system. This will allow the study of the influence of regression of canopy properties on SCPP efficiency. The standard equation used for modeling the SCPP is reported in many references such as $[6,11,30]$.

The effective produced power of the overall system can be expressed as:

$$
W_{\text {eff }}=\eta_{\text {coll }} \eta_{\text {turb }} \eta_{\text {ch }} A_{\text {coll }} I_{0}
$$

Based on energy balance, the solar heat transferred to the air from inlet to outlet can be expressed as:

$$
\eta_{\text {coll }}\left(A_{\text {coll }} I_{0}\right)=\dot{m} c_{p} \Delta T
$$

with the turbine loaded to the total power:

$$
v_{c h}=\sqrt{\frac{\left(1-\eta_{t u r b}\right) 2 g H_{c h} \Delta T}{T_{0}}}
$$

Combining the previous equations and conservation equations of the collector and the chimney and rearranging them leads to:

$$
c_{1}\left(\frac{\Delta T^{3 / 2}}{1+\frac{\Delta T}{T_{0}}}\right)+c_{2} \Delta T+c_{3}=0
$$

with

$$
c_{1}=\rho_{0} c_{p} \sqrt{\frac{\left(1-\eta_{t u r b}\right) 2 g H_{c h}}{T_{0}}}
$$

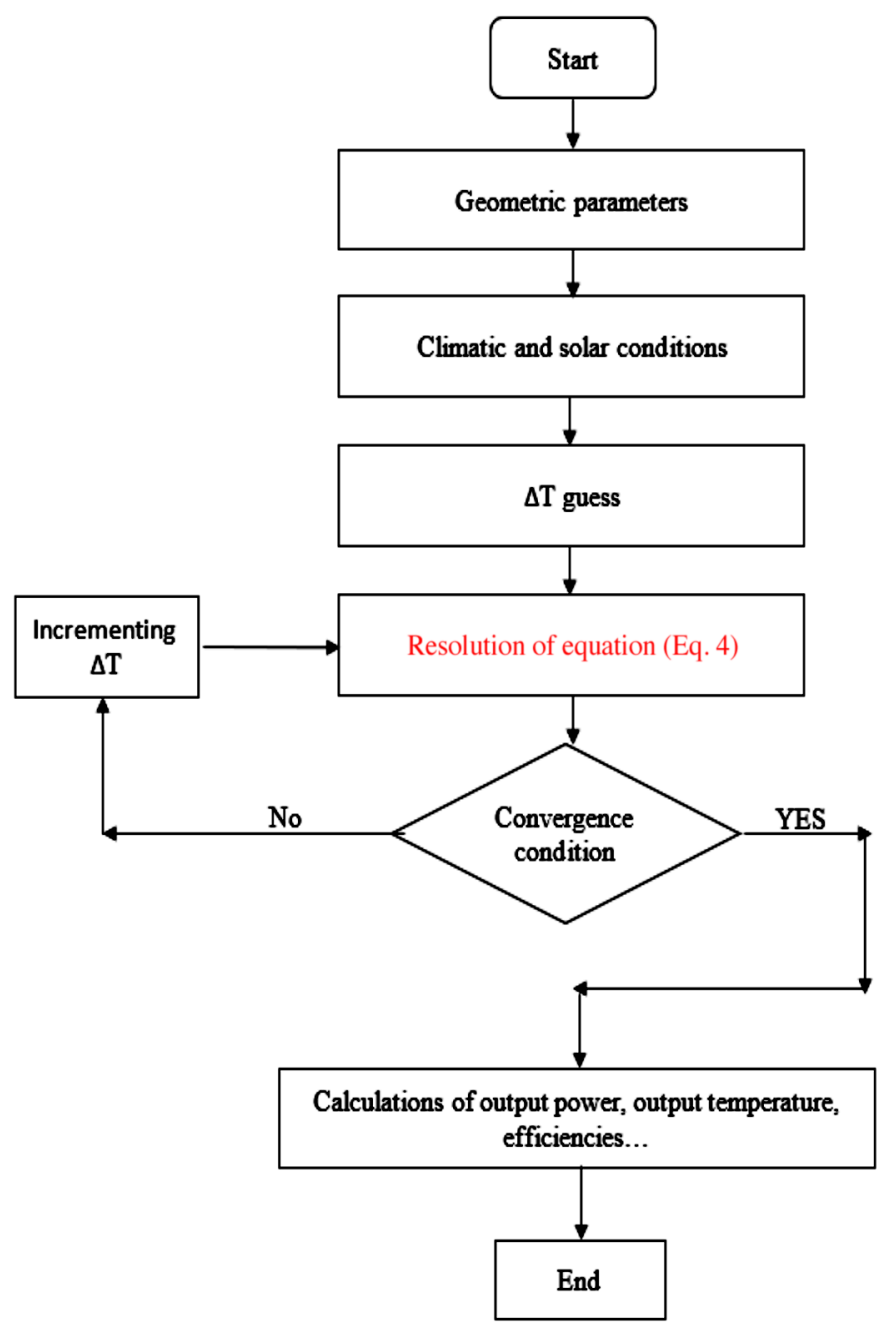

Fig. 17. Flowchart of resolution.

$$
\begin{gathered}
c_{2}=-\beta \frac{A_{\text {coll }}}{a} \\
c_{3}=-\tau \alpha \frac{A_{\text {coll }}}{a} I_{0}
\end{gathered}
$$

Equation (4) is solved numerically using the Range Kutta method. It is illustrated by the flowchart of resolution in Figure 17 (Tab. 4).

\section{Calculation and analysis}

In order to validate the presented model, Manzanares solar chimney measured parameters are taken as reference. The technical data are given in Table 3.

The comparison between measured data from Manzanares Solar Chimney Pilot Power Plant and the simulation shows a good agreement. The technical data given in Table 3 are used for the following simulation and analysis. The simulation of the SCPP using a low-density polyethylene as a collector cover revealed a decrease of the collector thermal efficiency and the overall system 


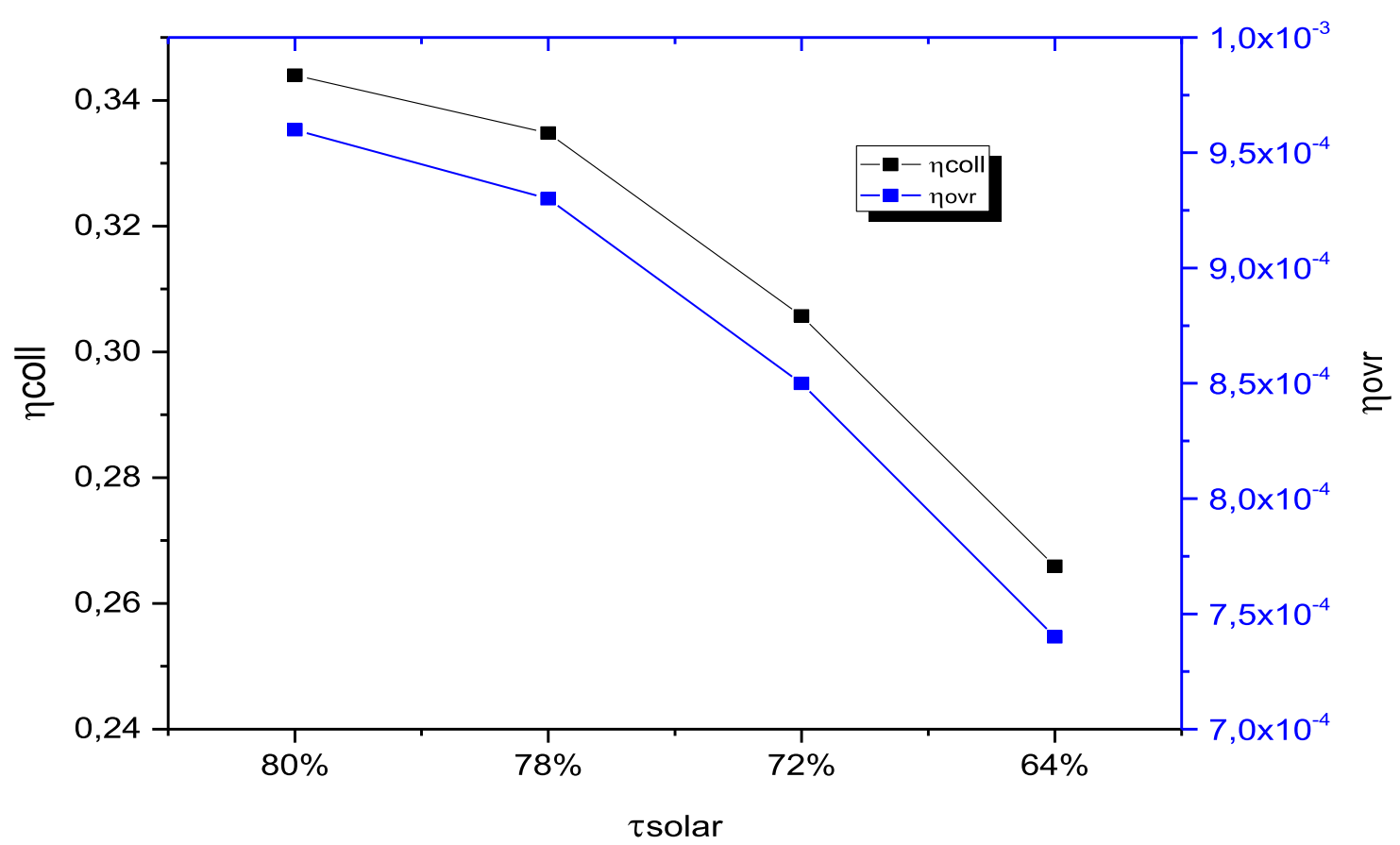

Fig. 18. Overall SCPP and collector efficiency evolution for LDPE canopy: New sample $(\boldsymbol{\tau}=80), 1$ year old $(\boldsymbol{\tau}=78), 2$ years old $(\tau=72)$ and 3 years old $(\tau=64)$.

Table 3. Typical solar chimney power plant data and dimensions used in the simulation.

\begin{tabular}{ll}
\hline Geometrics parameters & $\begin{array}{l}\text { Manzanares } \\
\text { prototype }\end{array}$ \\
\hline Collector height $\mathrm{h}[\mathrm{m}]$ & 1.85 \\
Collector diameter $\mathrm{D}_{\text {coll }}[\mathrm{m}]$ & 244 \\
Chimney height $\mathrm{H}_{\mathrm{ch}}[\mathrm{m}]$ & 194.6 \\
Chimney diameter $\mathrm{d}_{\mathrm{ch}}[\mathrm{m}]$ & 10.16 \\
Turbine efficiency $\eta_{\text {turb }}[\%]$ & 83 \\
Gearing and generator efficiency [\%] & 90 \\
Collector roof solar transmittance $\tau[\%]$ & 87 \\
Collector absorbance $\alpha[\%]$ & 0.76 \\
Collector loss coefficient $\beta\left[\mathrm{W} / \mathrm{m}^{2} \cdot \mathrm{K}\right]$ & 15 \\
Ambient conditions & \\
Ambient temperature $[\mathrm{K}]$ & $18+273.15$ \\
Gravitational acceleration $\left[\mathrm{m} / \mathrm{s}^{2}\right]$ & 9.81 \\
Solar irradiation $\left[\mathrm{W} / \mathrm{m}^{2}\right]$ & 1000 \\
Cp Specific heat of air $[\mathrm{J} / \mathrm{kg} \cdot \mathrm{K}]$ & 1004 \\
\hline
\end{tabular}

*Estimated from Yogi [32].

efficiency through the years (Fig. 18). In fact, the film transmittance decrease reduces the thermal efficiency of the system over the years.

The overall system efficiency also decreases from $\boldsymbol{\eta}_{\text {ovr }}=0.096 \%$ for anew sample to $0.074 \%$ for three years old sample (36 months). In fact, the reduction of the collector efficiency impacts the energy transmitted to the
Table 4. Comparison between measured and calculated values.

\begin{tabular}{lll}
\hline Parameters & Measured $^{*}$ & Calculated \\
\hline$\Delta \mathrm{T}\left[{ }^{\circ} \mathrm{C}\right]$ & 19,5 & 18,8 \\
Weff $[\mathrm{kW}]$ & 48,4 & 49,32 \\
$v_{c h}[\mathrm{~m} / \mathrm{s}]$ & 15 & 14,5 \\
\hline
\end{tabular}

*Measured values from Mullett [30] and Koonsrisuk et al. [31].

air inside the canopy. The collector efficiency decreases by $11 \%$ after 2 years exposure, and $23 \%$ after 3 years as shown in Figure 18. This impacts the air temperature gain inside the collector. The temperature decrease $(\Delta \mathrm{T})$ decreases by about $2 \%, 8 \%$ and $16 \%$ after one, two and three years of exposure respectively (see Fig. 19).

A gradual reduction in the produced effective power is observed (Fig. 19). The loss in production reaches $23 \%$ for the $3 \mathrm{rd}$ year corresponding to a lack of production of $10 \mathrm{~kW}$ for an irradiation peak of $\mathrm{I}_{0}=1000 \mathrm{~W} / \mathrm{m}^{2}$.

In order to maintain the initial energy production (case of low-density polyethylene) when keeping the same properties of the Manazanares plant, it is necessary to estimate, during the design phase, either an additional height of the chimney or an additional surface of the collector to compensate the loss of energy production due to aging. To demonstrate this, the mathematical code was executed varying the height of the chimney.

Figure 20 shows that the power and air velocity are proportional to the chimney height. Indeed, the updraft velocity is proportional to the chimney height Hch (Eq. (3)). 


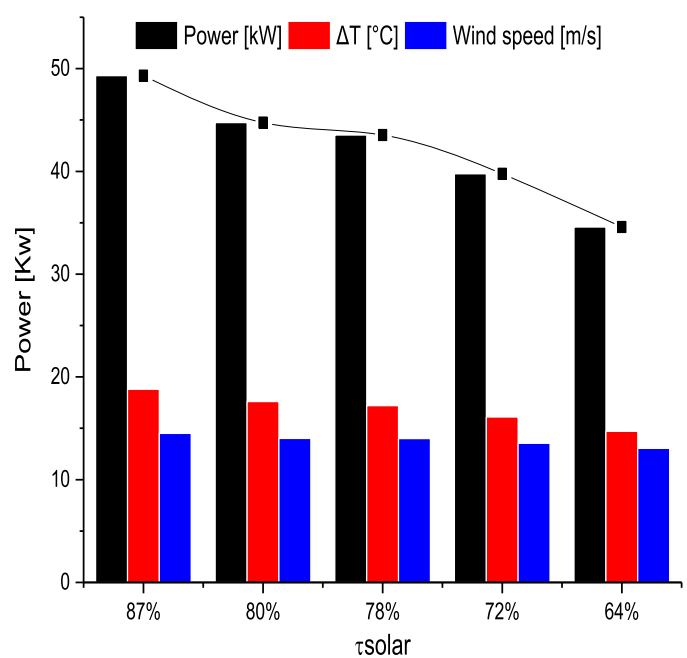

Fig. 19. Manzanares SCPP simulation output for glass $(\boldsymbol{\tau}=87)$ and LDPE canopy: New sample $(\boldsymbol{\tau}=80)$, one year old $(\boldsymbol{\tau}=78)$, two years old $(\tau=72)$ and three years old film $(\tau=64)$ respectively.

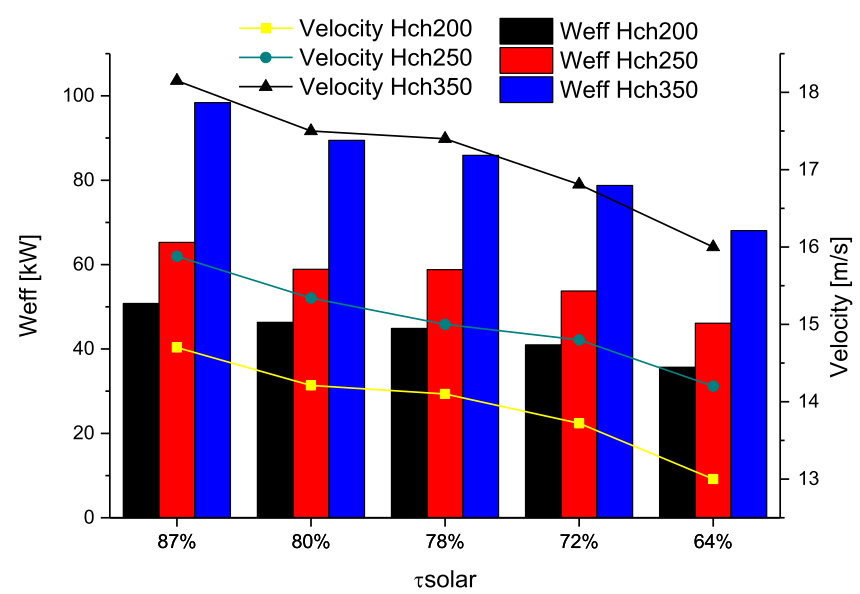

Fig. 20. Developed power and updraft velocity for different $H_{c h}$.

This leads in an increase of air flow inside the system and consequently to the produced power. Increasing the surface of the collector demonstrates an increase in the effective power produced due to an increase in the temperature gain (Fig. 21).

In fact, by increasing the diameter of the collector, i.e. the surface receiving the incident radiation, additional energy is transmitted to the air under the canopy, thereby improving the thermal gain. The temperature difference $(\Delta \mathrm{T})$ and the power produced are proportional to the area of the collector (Eqs. (1) and (2)).

To ensure continuous production of the design power of $44.74 \mathrm{~kW}$ for a life cycle of 3 years $(\tau=64 \%)$, two solutions are possible: either to increase the initial height of the chimney by $45 \mathrm{~m}$, resulting in a $23 \%$ increase in the chimney height, comparatively to the initial value; or to increase the diameter of the collector by $28 \mathrm{~m}$, i.e. the initial collector area by $276 \mathrm{~m}^{2}$, resulting in an increase of $22 \%$ compared with the reference surface.

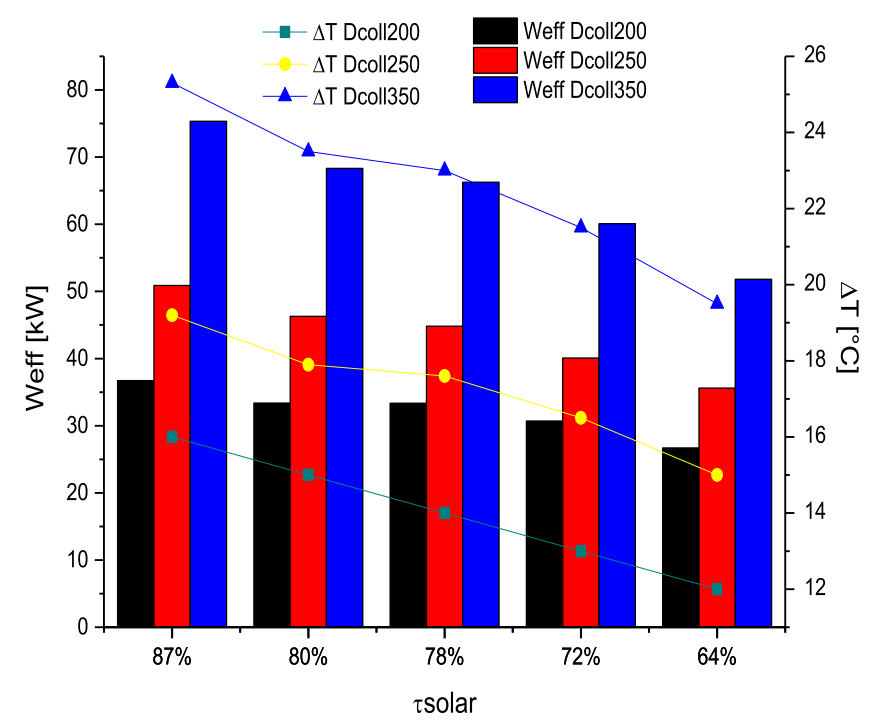

Fig. 21. Developed power and thermal gain for different $D_{\text {coll }}$.

\section{Conclusion}

This study investigated the implementation of polymers LDPE, as a roof coverage for a solar chimney power plantwith the aim to reduce the initial investment cost. The obtained results related to the analysis and comparison of the different tests carried out on new and aged samples showed that:

- The mechanical tests (tensile and hardness) illustrate a significant loss on the properties after exposure of three years. These results were confirmed by the spectroscopic tests showing the progress of film degradation as a function of time.

- Pyranometric measurements indicate that the transmittance of the film decreases as a function of the duration of aging. A notable decrease in the transmittance performance is noted after 3 years of exposure.

- Two dimension changes to account for the loss of efficiency over time are investigated: increasing chimney height and collector area.In order to offset the significant cost linked to building concrete-made chimney, and for structural constraints, to compensate the loss in production during plant exploitation, an additional collector surface is recommended. In the case of an LDPE this can go up to $22 \%$ of the initial surface.

- The use of polymers as a core for the collector of experimental prototypes, model validation, and simulation over a life cycle exceeding one year must be revised.

- The models should take into consideration the degradation of the properties of this type of material that often result in a reduction of the system efficiency.

- The present work paves the way for modeling the SCPP collectors, including aging effects, which lead to a better design of the system, taking into consideration the reduction of the SCPP performance through its life cycle. 


\section{Nomenclature}

Latin symbols

$A \quad$ Total covered area $\left[\mathrm{m}^{2}\right]$

a Chimney area $\left[\mathrm{m}^{2}\right]$

$D$ Diameter $[\mathrm{m}]$

I Global solar radiation $\left[\mathrm{W} \mathrm{m} \mathrm{m}^{-2}\right]$

$H$ Height $[\mathrm{m}]$

$P$ Power [W]

$Q \quad$ Heat flux [W]

$T$ Temperature [K]

$c_{p} \quad$ Specific heat at constant pressure $\left[\mathrm{J} \mathrm{kg}^{-1} \mathrm{~K}^{-1}\right]$

$g \quad$ Gravitational acceleration, $9.81\left[\mathrm{~m} \mathrm{~s}^{-2}\right]$

$\dot{m}$ Mass flow [kg s-1]

$p \quad$ Pressure $\left[\mathrm{N} \mathrm{m}^{-2}\right]$

$v \quad$ Velocity $[\mathrm{m} \mathrm{s}-1]$

$W$ Work [W]

$R \quad$ Air gas constant $[\mathrm{J} / \mathrm{k} \mathrm{mol}]$

Greek symbols

$\rho$ Density $\left[\mathrm{kg} \mathrm{m}^{-3}\right]$

$\eta$ Efficiency [-]

$\tau$ Collector solar transmittance [-]

$\alpha$ Collector absorbance [-]

$\beta$ Collector loss coefficient $\left(\mathrm{W} / \mathrm{m}^{2} \mathrm{~K}\right)$

Prefix

$\Delta$ Change in value

Subscript

$0 \quad$ Ambient or Incident

coll Collector

ch Chimney

eff Effective

ovr Overall

turb Turbine

\section{References}

1. Gianpaolo Vitale, Renewable energies - future perspectives renewable, Energy Environmental Sustainability 1, 17 (2016)

2. https://www.energy.gov.dz/?rubrique=energies-nouvellesrenouvelables-et-maitrise-de-lrenergie

3. M.A. Dos Santos Bernardes, Solar chimney power plantsdevelopments and advancements, INTECH Open Access Publisher, 2010

4. W. Haaf, K. Friedrich, G. Mayr, J. Schlaich, Solar chimneys, part I: principle and construction of the pilot plant in Manzanares, Int. J. Solar Energy 2, 3-20 (1983)

5. W. Haaf, Solar chimneys, part II: preliminary test results from the Manzanares pilot plant, Int. J. Solar Energy 2, 141-161 (1984)
6. J. Schlaich, The Solar Chimney (Axel Menges Edition, Stuttgart, Germany, 1995)

7. J. Schlaich, R. Bergermann, W. Schiel, G. Weinrebe, Design of commercial solar tower systems - utilization of solar induced convective flows for power generation, in: Proceedings of the International Solar Energy Conference, Kohala Coast, United States, 573-581 (2003)

8. J. Schlaich, W. Schiel, Solar Chimneys, Encyclopedia of Physical Science and Technology 3, 99-109 (2004)

9. Y.L. Wei, Z.K. Wu, Shed absorbability and tower structure characteristics of the solar heated wind updraft tower power, in: 3rd International Conference on Solar Updraft Tower Technology, Huazhong University Of Science And Technology, Wuhan, China, 1-12 (2012)

10. M. Najmi, A. Nazari, H. Mansouri, G. Zahedi, Feasibility study on optimization of a typical solar chimney power plant, Heat Mass Transfer 48, 475-485 (2012)

11. S.M. Boualleg, S. Larbi, Analyse des performances énergétiques des centrales cheminées solaires par utilisation de différents modèles mathématiques. ENP (2012). www.pnst. cerist.dz/detail.php?id $=68739$

12. D. Eryener, J. Hollick, H. Kuscu, Thermal performance of a transpired solar collector updraft tower, Energy Conversion and Management 142, 286-295 (2017)

13. D. Eryener, H. Kuscu, Hybrid transpired solar collector updraft tower, Solar Energy 159, 561-571 (2018)

14. A. Ayadi, A. Bouabidi, Z. Driss, M. Salah Abid, Experimental and numerical analysis of the collector roof height effect on the solar chimney performance, Renewable Energy 115, 649-662 (2018)

15. A.B. Molana Sh., K. Rahmani, D. Wen, A review on solar chimney systems, Renewable and Sustainable Energy Reviews 67, 954-987 (2017)

16. P. Guoa, T. Li, B. Xu, X. Xuc, J. Li, Questions and current understanding about solar chimney power plant: a review, Energy Conversion and Management 182, 21-33 (2019)

17. H.H. Al-Kayiem, M.A. Aurybi, S.I.U. Gilani, A.A. Ismaeel, S. T. Mohammad, Performance evaluation of hybrid solar chimney for uninterrupted power generation, Energy 166, 490-505 (2019)

18. H. Nasraoui, Z. Driss, H. Kchaou, Novel collector design for enhancing the performance of solar chimney power plant, Renewable Energy 145, 1658-1671 (2020)

19. S. Jamali, A. Nemati, F. Mohammadkhani, M. Yari, Thermal and economic assessment of a solar chimney cooled semitransparent photovoltaic (STPV) power plant in different climates, Solar Energy 185, 480-493 (2019)

20. S. Hossein Fallah, M. Sadegh Valipour, Evaluation of solar chimney power plant performance: the effect of artificial roughness of collector, Solar Energy 188, 175-184 (2019)

21. A. Asghar Sedighi, Z. Deldoost, B. Mahjoob Karambasti, Effect of thermal energy storage layer porosity on performance of solar chimney power plant considering turbine pressure drop, Energy 194, 116-859 (2020)

22. G. Papadakis, D. Briassoulis, G. Scarascia Mugnozza, G. Vox, P. Feuilloley, J.A. Stoffers, Radiometric and thermal properties of, and testing methods for, greenhouse covering materials, J. Agric. Eng. Res. 77, 7-38 (2000)

23. A. Dehbi, A.-H.I. Mourad, Durability of mono-layer versus tri-layers LDPE films used as greenhouse cover: comparative study, Arab. J. Chem. 9, S282-S289 (2016) 
24. P.A. Dilara, D. Briassoulis, Standard testing methods for mechanical properties and degradation of Low Density Polyethylene (LDPE) films used as greenhouse covering materials: a critical evaluation, Polym. Test. 17, 549-585 (1998)

25. P. Nicaud, Les Matière Plastiques. Projet Troisième Rob'Ok, Hachette Multimédia (2007)

26. R. Irinislimane, N. Belhaneche-Bensemra, A. Benlefki, Valorization of regenerated LDPE by blending with EPDM in the presence of peroxide, J. Polym. Environ. 15, 119-124 (2007)

27. A.A. Babaghayou, I.M. Chabira, S.F. Sebaa, M., Impact of solar radiation effects on the physicochemical properties of Polyethylene (PE) plastic film, Soc. Behav. Sci. 195, 2210-2217 (2015)
28. Recueil de normes ISO21-TOM1 \& TOM2, Plastiques: Technologie-échantillonnage et propriétés, 1984 (Recueil de normes ISO 21, 1984)

29. S. Füzesséry, Polyéthylènes basse densité PEBD. Techniques de l'ingénieur, Novembre 1983

30. L.B. Mullett, The solar chimney overall efficiency, design and performance, Int. J. Ambient Energy 8, 35-40 (1987)

31. A. Koonsrisuk, T. Chitsomboon, Mathematical modelling of solar chimney power plants, Energy 51, 314-322 (2013)

32. D. Yogi Goswami, Principles of solar engineering Taylor \& Francis Group, 6000 Broken Sound Parkway NW, Suite 300, USA

Cite this article as: Salim Mekki Boualleg, Salah Larbi, Amor Bouhdjar, Dalila Amokrane, Abdallah Sofiane Berrouk, Influence of environment and aging materials on the performance of solar chimney power plants, Renew. Energy Environ. Sustain. 6, 11 (2021) 